\title{
TEORIAS DO CURRÍCULO: REFLEXÕES SOBRE AS SUAS INFLUENCIAS NO PROCESSO DE ESCOLARIZAÇÃO
}

\author{
CURRICULUM THEORIES: REFLECTIONS OF THEIR INFLUENCE IN THE SCHOOLING \\ PROCESS
}

\begin{abstract}
TEORÍAS DEL CURRÍCULO: REFLEXIONES DE SUS INFLUENCIAS EN EL PROCESO DE ESCOLARIZACIÓN
\end{abstract}

Claudia Regina Castellano Losso ${ }^{1}$ Martha Kaschny Borges ${ }^{2}$

${ }^{1}$ Doutoranda em Educação pela Universidade do Estado de Santa Catarina (UDESC), Florianópolis, SC, Brasil.

${ }^{2}$ Doutora em Educação pela UPMF. Docente do Programa de Pós-Graduação em Educação da Universidade do Estado de Santa Catarina (UDESC), Florianópolis, SC, Brasil.

Resumo: Este estudo busca uma reflexão teórica sobre currículo no processo de escolarização, baseando-se em três textos de autores renomados na área, Joseph Schwab, José Augusto Pacheco e Michael Young. Traz como base para discussão os escritos sobre currículo, sendo eles "Un enfoque práctico como lenguaje para el currículum" de Schwab (1992); "Curriculum studies: what is the field today?" de Pacheco (2012) e "Currículo: conhecimento e avaliação" de Young (2013). Discorre sobre os principais tópicos de cada autor sobre o tema e aponta caminhos para a sua análise, ao entender que este é um campo específico de tensões, de disputas, de interesses.

Palavras-chave: Currículo; Processo de Escolarização; Educação.

Abstract: This study offers a theoretical reflection on curriculum in the schooling process, based on three texts by renowned authors in the area; Joseph Schwab, José Augusto Pacheco and Michael Young. As a basis for discussion, it brings their writings on curriculum, " Un enfoque práctico como lenguaje para el currículum " by Schwab, (1992); "Curriculum studies: what is the field today?" by Pacheco (2012) and "Curriculum: knowledge and evaluation" by Young (2013). It discusses the main topics covered each author on the subject, and points out ways of analyzing it, understanding that this is a specific field of tensions, disputes, and interests.

Keywords: Curriculum; Schooling process; Education.

Resumen: Este estudio busca una reflexión teórica sobre el currículo en el proceso de escolarización, basándose en tres textos de autores renombrados en el área, Joseph Schwab, José Augusto Pacheco y Michael Young. Se trae como base para la discusión los escritos sobre currículo, siendo ellos, "Un enfoque práctico como lenguaje para el currículum" de Schwab, (1992); "Currículo: conocimiento y evaluación" de Young (2013). Se aborda sobre los principales tópicos de cada autor sobre el tema y señala caminos para su análisis, al entender que éste es un campo específico de tensiones, de disputas, de intereses. 
Palabras clave: Currículo; Proceso de escolarización; Educación.

Este ensaio teórico traz como base para discussão os escritos sobre currículo, sendo eles: "Un enfoque práctico como lenguaje para el currículum" de Joseph Schwab, (1992); "Curriculum studies: what is the field today?" de José Augusto Pacheco (2012) e "Currículo: conhecimento e avaliação" de Michael Young (2013). Trata-se de um recorte de estudos desses renomados teóricos do campo do currículo e que não pretende esgotar o tema, mas destacar a importância na compreensão dos papéis dos atores e das instâncias que cercam o debate sobre o campo.

Nos textos em debate, cada autor, a seu tempo, ligado a suas inclinações teóricas e até mesmo relacionais, dentro daquilo que se tem como campo dos estudos curriculares, traz três pontos a serem destacados: i) o espaço (ou a ausência) de debate sobre o conhecimento como eixo central do campo; ii) o persistente distanciamento entre as ocupações teóricas e práticas dos estudiosos do campo; e iii) o próprio estado do campo como arena complexa e plural.

Para iniciar essa conversa, faz-se necessário trazer para o centro dessa reflexão o entendimento do que é currículo. Apesar das teorias do currículo apontarem diversos caminhos do que venha a sê-lo, todos concordam que o currículo está fortemente entrelaçado com o que a escola deve ensinar. No entanto, não há um consenso sobre isso, mas todos comungam de uma 'verdade', ainda que provisória, que o currículo é um elemento organizador tanto das rotinas quanto do fazer pedagógico do professor e do aluno, definindo caminhos, corroborando trajetórias e demonstrando aos seus atores o que se quer deles.

O currículo, além de indicar o que a escola deve ensinar, define quando, como e por que ensinar determinado conteúdo e não outro e a forma como se deve avaliar. Ainda possui como substância diferenciada e específica o conhecimento escolar que obrigatoriamente é selecionado, organizado e sequenciado, trazendo de certa forma uma ordem a ser seguida.

Apesar das diversas teorias do currículo, em suas perspectivas ou abordagens sejam elas, racionalistas, críticas ou pós-críticas, percebe-se que o campo parece ser afetado por uma crise permanente, constituída por diversos fatores e pelas tensões entre os diferentes paradigmas. O currículo, sempre arbitrado por alguém ou alguma força social, política ou econômica, sofre mudanças, que obrigatoriamente definem a sua rota, e as tensões que se estabelecem, se entrelaçam nos fazeres e nos saberes que envolvem os processos de escolarização.

Enfim, esse ensaio busca realizar uma breve reflexão sobre as interfaces que perpassam o currículo, a partir dos diversos estudos teóricos forjados em diferentes tempos históricos, sejam eles em defesa do sagrado, da racionalidade, da crítica e das subjetividades desveladas nos tempos das ditas novas tecnologias e outras tensões que constituíram o campo, numa sociedade que se denomina hoje como a 'sociedade do conhecimento'.

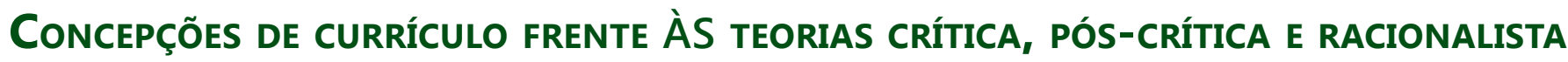

O problema do campo do currículo se caracteriza, como mesmo lembra Pacheco, apoiado em alguns atores (Mcneil,1978; Vallance, 1982; Jackson, 1992; Pinar, 2004; Alex Molnar,1992; 
Joseph Schwab, 1970 e Lawrence Stenhouse,1983; William Schubert, 2009), à mercê das tensões dos tempos históricos cujos estudos do campo se constituem e se organizam considerando os aspectos que os afetam, definindo como foram sendo concebidos e por que não dizer, implementados. Ainda o mesmo autor aponta que os estudos do campo, além de ser uma tarefa complexa e controversa, não escapam à discussão epistemológica cujas abordagens do currículo como teoria e currículo como processo apontam as divergências e as diferentes visões sobre o campo.

No entanto, essa discussão desvela a necessidade de se compreender a escola nos mais diferentes tempos históricos e apesar da sensação que ela é a mesma, parecendo congelada a um olhar mais desavisado, é importante se destacar que esse lugar traz a marca de uma cultura própria que a caracteriza como espaço de saberes e poderes e por isso, marcada por interesses políticos, sociais, econômicos, filosóficos, culturais de seu tempo. Em função disso, é pertinente se questionar o que é, por que, para que e para quem a escola se destina?

A escola necessita ser pensada, assim como deve ser pensado o currículo. Compreender quais as demandas, quem são os alunos, quais as metodologias e, principalmente, como dirimir as desigualdades ainda tão acentuadas é tarefa árdua, mas necessária para que se entenda o processo de escolarização e suas interfaces com o campo do currículo. Para endossar essa reflexão, pediu-se auxílio para Silva e Mendes, que discutem sobre a especificidade que caracteriza a escola,

[...] os estudiosos da área do Currículo que se ocupam de temas como reforma curricular há muito apontam para a necessidade de entendermos as especifidades da escola. Nesse sentido, nos parece que a despeito dessas diferençiadas abordagens há sempre presente um elemento quando o objeto de estudo é a escola, qual seja, o reconhecimento da existência de uma cultura própria dessa instituição. Cultura essa que a conforma de uma maneira muito particular, com uma prática social própria e única.(SILVA; MENDES, 2014, p.180)

A escola e suas especificidades são vistas por Michael Young, marxista crítico, de um modo particular, em que o conhecimento tem papel fundamental no sentido de uma escola emancipatória, sendo ele uma ferramenta poderosa contra o relativismo.

Young (2013), cuja contribuição está enraizada na nova sociologia da educação, defende que os estudos do currículo deverão ser discutidos sob a égide do que deve ser ensinado e aprendido na escola, bem como sobre o direito do aluno em ter acesso ao conhecimento poderoso e, assim, definindo como conhecimento que deverá constituí-lo.

Nesses termos, o curriculista desenha uma concepção de currículo baseado no conhecimento, definindo os seguintes princípios que deverão nortear as discussões sobre o campo:

1. Sua forma de especialização: diferença e integralidade entre o conhecimento poderoso - especializado e o conhecimento recontextualizado - o conhecimento escolar.

2. A relação entre currículo nacional e os currículos individuais das escolas - a garantia que mesmo mudando de escola o aluno vai se encontrar apoiado a um currículo mínimo. Contudo esse currículo nacional trará somente diretrizes, trazendo os conceitos-chaves das disciplinas. Assim, as escolas poderão organizar seus currículos 
locais, garantindo a autonomia das escolas.

3. A diferença entre conhecimento conceitual (currículo) e o conhecimento do conteúdo (cotidiano) - a integralidade dos dois permite a ampliação das trajetórias educacionais dos alunos.

4. A diferença entre pedagogia e currículo: os alunos não vêm a escola para aprender o que já sabem pela experiência. O currículo não inclui o conhecimento tácito dos alunos, apesar de que o mesmo seja muito importante para que o professor organize as estratégias de aprendizagem.

Pacheco (2012), ao realizar um pequeno mas significativo levantamento do estado da arte sobre os estudos do campo do currículo, levanta (como já apontamos) que compreender o currículo é tarefa complexa e controversa. Há divergências entre teoria e prática, e o discurso e a prática. No entanto, destaca que o currículo é uma conversa local, nacional e internacional, sua concepção depende das palavras daqueles que o fazem no contexto e por isso endossa o que Madeleine Grumet (1988, p 122) coloca que "o problema de estudar o currículo é que somos o currículo".

Discute ainda que não há uma concepção fechada porque o estado do campo é apenas um momento especial, uma intersecção ou entrecruzamento do presente e do passado e, por isso, moldado por diferentes perspectivas. Pacheco então, a partir das contribuições de Schubert (2009, p. 176), coloca as questões desse teórico 'O que é que vale a pena? O que vale a pena conhecer, experimentar, precisar, fazer, ser, tornar-se, superar, compartilhar e contribuir? Como poderão nos auxiliar na definição do que hoje concebemos currículo?'.

Schwab (1970) já apontava críticas ao modelo de como as escolas estão pensando e elaborando o currículo. De início indica as potenciais causas de crise, como sendo o currículo um espaço morto, desvitalizado, inabitado, bem como sinaliza o excesso de confiança no currículo, sem que o mesmo seja visto, revisto, melhorado e ainda propõe as taxonomias de elaboração curricular. Em relação às teorias para implementação do currículo, o autor expõe a necessidade da ampliação do olhar e da sensibilidade para perceber que as teorias isoladas colocam o aluno na situação de inércia em relação à escola, pois cada teoria tende a olhar para uma parte da construção da pessoa, excluindo outras. Essa perspectiva é a mais remota do currículo e traz para a discussão de um currículo prescrito, que desqualifica os atores da prática curricular.

Partindo dessa breve exposição sobre a construção de uma concepção de currículo, considerando as três principais abordagens, crítica, pós-crítica e racionalista, foram verificadas algumas pistas de como o currículo vem sendo concebido e de como ele foi sendo implantado nas salas de aulas nos mais diferentes tempos históricos.

Contudo, é importante lembrar que o campo do currículo é um lugar de disputa de todas essas concepções e por esse motivo se faz necessário que as intervenções e as leituras do campo sejam realizadas de forma crítica, no intuito de se percebe a que está presente e que forças (econômicas, políticas, sociais, culturais...) organizam as práticas curriculares nas escolas.

Partindo disso, em seguida se tratará de apontar como o currículo vem se constituindo como campo e quais são as tensões as quais se está sujeito, interferindo direta ou indiretamente no que se deve ensinar e aprender nas escolas hoje. 


\section{A CONSTRUÇÃO DO CURRÍCULO COMO CAMPO}

As primeiras teorias do currículo se iniciaram nos anos 20 do século passado, com o estudioso Franklin John Bobbitt, quando escreve o livro "The Curriculum". Baseado na perspectiva Tayloriana de administração nos EUA, e sua aplicabilidade na educação, esta obra inicia os estudos sobre currículo e também a corrente tradicional. Fundamentando-se nos conceitos de Bobbitt, Ralf Tyler, autor de "Princípios Básicos de Currículo e Ensino", escrito nos anos 40 , se propõe a desenvolver uma base racional para considerar, analisar e interpretar o currículo e o programa de ensino de uma instituição educacional (Tyler, 1974). Ambos tinham em mente uma reforma para uma escola de massa, baseada em uma pedagogia científica.

A Racionalidade de Tyler, como ficou conhecida sua abordagem teórica, fundamenta a construção de propostas curriculares até os dias atuais e estrutura o currículo a partir da visibilidade, do controle e da vigilância das práticas escolares. Visando determinar comportamentos, Tyler compreende o currículo como o conjunto de objetivos educacionais e conteúdos que se concretizam a partir dos objetivos.

Considerado um novo paradigma, essa abordagem privilegia os interesses da sociedade em detrimento aos da criança. Essa forma de pensar o currículo, até então descritivo, encontrava apoio na Escola de Chicago, em nome da eficácia da educação baseada num modelo neoliberal de economia.

As críticas à Racionalidade Tyleriana, como ficou conhecida, partiu de um movimento por uma nova sociologia. Na Inglaterra, onde Young acredita que o modelo Tyleriano não teve uma influência tão grande, havia também um movimento contra a forma de compreender o currículo imposta pelo paradigma da racionalidade de Tyler.

Willian Pinar, Michael Apple, Ivor Goodson, e entre outros intelectuais, iniciam um movimento crítico contrário à perspectiva tradicional e denominados conceitualistas ou críticos, ou mesmo pós-estruturalistas. Com defesas distintas da concepção de conhecimento, Young, Apple, Goodson e Berstein partem da perspectiva crítica para ajudar a construir a teoria crítica na Inglaterra.

Goodson parte de um currículo autobiográfico e seu posicionamento se aproxima mais de Pinar do que de Young. Goodson reconhece que o conhecimento é também penetrado pelo poder, leitura esta que parte das análises de Michel Focault e Pierre Bordieu. Para o autor, a agência não está na escola ou na sala de aula, mas no professor, que deve ter papel fundamental nas reformas educacionais e curriculares.

Outro movimento que faz a crítica ao modelo tradicional e aos empiristas como Schawb, o movimento reconceitualista, é pautado na perspectiva pós-estruturalista, baseada nos estudos de Willian Pinar e Goodson. Este movimento conta com intelectuais críticos marxistas como Young, Berstein e Bordieu.

Apple e Pinar, reconceitualistas, mas com perspectivas teóricas totalmente distintas; Pinar, pós-estruturalista com base nos estudos focaultianos; e Apple fundamenta-se na concepção marxista. Pinar fundamenta seus estudos no movimento contra os tradicionalistas e na negação da primazia das orientações políticas no currículo (Pacheco, 2012) 
Os desafios atuais de identidade, gênero, raça, etnias, dominam as discussões hoje acerca do currículo, em especial pelo grupo oriundo dos estudos de Pinar. A preocupação com o desenvolvimento curricular praticamente desapareceu do cenário, passando a predominar o propósito de compreender o processo curricular (Pinar et al., 1995).

Diferenciando-se de Goodson, Young afirma que o campo está confuso e diversificado, criando "comunidades de especialistas", cada uma com diversos modos de trabalhar, mas afirma que mesmo assim estes precisam determinar o que deve ser ensinado nas escolas. Essa passagem da teoria do currículo da Racionalidade de Tyler (tecnicista) para um novo enfoque de crítica (ideológica) Young, criticando os pós-críticos, afirma que se está perdendo rapidamente o objeto principal dos estudos curriculares (Young, 2013, p. 15), ou seja, "o que é ensinado e aprendido na escola e, portanto o seu papel de destaque nos estudos educacionais".

Continua o texto, afirmando que com essa abertura do campo para qualquer especialista, de áreas como filosofia, literatura e estudos culturais, faz com que a escola perca seu objeto, sua especificidade. Numa crítica clara aos pós-críticos como Pinar "e seus seguidores", Young levanta duas consequências dessa abertura do campo na Inglaterra: os autores levantam questões sobre cultura e identidade na sociedade moderna, mas pouco sobre a escola, ou sobre o currículo escolar e os governantes e os elaboradores do currículo não dão a devida atenção a quem estuda o currículo.

Young continua sua crítica, afirmando que, com os pós-estruturalistas, o campo se expande e tudo pode ser currículo, perdendo espaço para quem realmente tem o que dizer sobre o tema. Há uma clara dispersão e exacerbação do campo, e já que o próprio campo está confuso e não assume seu papel, outras vozes determinam o que deve ser feito.

\section{O CONHECIMENTO EM DEBATE}

Em meio à discussão sobre currículo, o conhecimento parece ser delegado a um segundo plano, assim como dito por Young e sua preocupação com a abertura do campo. Para o autor, o conhecimento poderoso deve estar a serviço da educação, alimentando significativamente o caráter emancipador da escola. Young indaga quais conhecimentos significativos os alunos terão alcançado por meio do currículo e afirma que os professores não podem escapar do elemento instrucional de seu papel, num retorno à perspectiva tradicional. O desafio do professor, que não é apenas transmissor do conhecimento, é de promover uma aprendizagem significativa, ampliando a leitura de mundo.

Ao falar do conhecimento 'poderoso', Young (2013, p.17) afirma que existe um medo nas escolas e que "o conhecimento pode liberar o aluno a ter novos pensamentos, ou pensamentos ainda não pensados", e reabre a discussão sobre qual a percepção sobre conhecimento que os professores têm.

Goodson, numa outra perspectiva, ao discutir qual conhecimento é válido, afirma que as narrativas globais não dão conta da escola e as narrativas locais, formadas pelo sentimento de pertencimento do professor e de seu grupo, podem ser a melhor opção na construção 
de um currículo que atenda às necessidades da escola e dos seus alunos, numa narrativa autobiográfica, individual.

A maior tensão entre as perspectivas crítica e pós-crítica está justamente na visão de currículo construído pelos seus representantes, sendo que a ênfase do último ao indivíduo se reflete, por exemplo, na forma de aprender dos alunos nativos digitais. A centralidade no aluno trazida pela utilização de equipamentos tecnológicos em sala de aula, por exemplo, não pode suplantar o papel do professor como transmissor do conhecimento. Para Young, ainda cabe aos elaboradores dos currículos a preocupação em definir o que deve ser ensinado, e aos professores o papel de ensinar.

Na perspectiva crítica de Michael Young, o autor traz a ideia de Bordieu de que "todo ato educativo é um ato de violência simbólica, carrega em si um arbitrário cultural", pois sempre haverá alguém determinando o que deve ser feito, incluindo aqui o campo dos estudos curriculares.

\section{O CuRRÍculo hoJe}

A tendência no campo do currículo atualmente está na internacionalização, no cosmopolitismo, e a mundialização dos estudos curriculares, que a partir dos estudos de Pinar é um movimento que pretende cuidar de problemas que sejam comuns, como a diversidade, a inclusão, a tolerância, as questões raciais, dentre outros.

Apesar de haver uma mesma estrutura comum tanto na escola e quanto na sala de aula, há uma diversidade no que é o currículo em ação, como decidido por professores e alunos em contextos específicos, uma vez que "o que realmente acontece nas salas de aula varia amplamente em todo o mundo".

A possibilidade de criar novos espaços de discussão e teorizar sobre estudos de currículo não pode confiar em um modelo centro-periferia de mundo cultura ou de estudos de currículo. Consequentemente, a internacionalização não significa a globalização, uma vez que pode ser descrita como um global.

O estudo sobre currículo é uma tarefa complexa e sofre uma discussão permanente tanto sobre seu estado teórico e a relação entre teoria curricular e desenvolvimento curricular.

É uma conversa local, nacional e internacional, cujas palavras são usadas por aqueles que direta e indiretamente estão fazendo o currículo no contexto. O problema-chave do currículo é o contraste entre a teoria e a prática, já que na maioria das vezes os estudiosos do currículo não o elaboram. Além dos já citados anteriormente, existe o problema das agendas às quais o currículo se submete.

Nas reformas curriculares já realizadas no Brasil, perceberem-se as tendências e as abordagens de cada período histórico muito claramente. Atualmente, no Brasil, há uma política educacional que propõe a reformulação do currículo com a construção de uma Base Nacional Comum Curricular (BNCC), homologada em 2016, que pretende organizar conteúdos mínimos para o ensino fundamental, com coerência ao sistema educacional e equidade no que tange 
ao acesso ao conhecimento. Partem de ações e demandas múltiplas, numa perspectiva crítica, mas na qual persiste o debate do campo do currículo, de um lado os interesses políticos e, de outro, filosóficos e epistemológicos. Nesse contexto, veem-se avanços, mas também retrocessos, pois há uma tendência da educação ao retorno do tradicionalismo numa perspectiva neo-Tyleriana.

No entanto, é importante a discussão sobre o papel do aluno, dos professores, enfim, da comunidade no campo, para que de fato se constitua como currículo vivo. Também se acredita ser essencial que o debate sobre o mesmo seja realizado entre esses atores na busca de uma ação-reflexão-ação sobre a melhor forma de aprender, conhecer, ter acesso, enfim diante das tensões que o mundo contemporâneo impõe.

Desse modo, partindo dos estudos do campo no quais se pautaram para a compreensão sobre as diversas concepções de currículo desenhadas até hoje, entende-se que a busca de uma escola cada vez mais democrática e acessível a todos se dará considerando-se os dois aspectos apontados por Young (2013), pela garantia do acesso ao conhecimento poderoso de um lado e de justiça social do outro, garantindo esse último pelo acesso do primeiro, numa perspectiva emancipatória de educação.

Por isso, precisa-se de fato trazer para o debate as concepções do campo do currículo, no intuito de se romper com as estruturas de um currículo racionalista que ainda habita os fazeres e os discursos pedagógicos, interferindo de forma impiedosa nos processos de escolarização.

\section{Considerações}

Os estudos sobre currículo apontam uma trajetória pautada em diversos momentos históricos, nos quais intelectuais o problematizaram de acordo com seus ideais filosóficos e ideológicos. De início, firmou-se na racionalidade, diante de um contexto industrial nos EUA, numa perspectiva de formação para o trabalho no qual o currículo deveria orientar uma eficiência na educação a serviço do poder econômico.

Num segundo momento, com a nova sociologia, estabeleceu-se a crise no campo, cuja racionalidade Tyleriana é contestada. A crítica ao modelo anterior se pauta na perspectiva de garantir um currículo mais aberto, abrindo o campo para uma fragmentação em muitas especializações, deixando-o confuso.

Um último momento, o pós-crítico preconiza um movimento de natureza humanística. Busca-se um novo modelo curricular, em que a diversidade, a alteridade, o gênero, entre outras questões, devem ser privilegiados, bem como um movimento de internacionalização, numa perspectiva global, em que o conhecimento começa a ser discutido de forma mais complexa. Há uma preocupação com qual conhecimento tem mais valor.

No entanto, a partir da leitura dos textos, percebeu-se que campo está perpassado por divergências e interesses pessoais, políticos, teóricos, filosóficos, interferindo diretamente no modus operandi da escola, afetando o papel do professor e do aluno. Também é visível o papel 
do conhecimento, ora como força emancipatória, ora como modo de submissão e controle dos atores envolvidos.

Além disso, há de se ter cuidado com os discursos pós-críticos que levam o currículo a uma confusão epistemológica que o funda numa era em que o currículo passa a ser tudo o que acontece na escola, deixando o discurso vazio, retornando aos velhos modelos de um currículo que se reduz apenas à seleção, ao sequenciamento e à execução de conteúdos, preocupados com a operacionalização, ligada à preocupação da dominação da técnica em detrimento de um olhar mais profundo e crítico sobre os significados que o currículo traz à práxis educativa.

Enfim, os estudos curriculares são um campo em aberto, de eterno debate, não "moribundo", conforme Schwab; porém "sombrio", de acordo com Philip Jackson. Pautadas nas diversas abordagens do campo, fica o alerta de que é necessário, para que se entenda a sua influência do seu modus operandi no processo de escolarização, como bem coloca alguns dos autores estudados, que se deve 'ouvir' os atores que o elaboram, como também os que o executam.

Uma última recomendação aos leitores é que, diante de um cenário encharcado pelas transformações contemporâneas, orientando mudanças na escola, com a invasão compulsória das ditas novas tecnologias da informação e da comunicação, o campo se encontra em constante ebulição e, por esse motivo, torna-se necessário se atentar a quem o campo deve 'escutar' e, sobretudo, quem dita as novas regras para o enfrentamento das novas tensões que afetam a escola, não perdendo de vista a importância de uma discussão epistemológica em detrimento de uma voltada somente ao processo de ensino e aprendizagem.

Muito embora os questionamentos em torno do currículo pareçam os mesmos, e que os seus intelectuais pertençam ao mesmo movimento, as respostas, às vezes, são totalmente diferentes. Em tempos distintos, cada um aponta o currículo como um campo específico de tensões, de disputas, de interesses.

\section{REFERÊNCIAS}

GRUMET, M. R. Bitter Milk: Women and Teaching. Amherst: The University of Massachusetts Press, 1988.

PACHECO, J. A. Curriculum Studies: What is The Field Today? Journal of The American Association for the Advancement of Curriculum Studies, v. 8, n. 1. p. 1-25, 2012. Disponível em: http://citeseerx. ist.psu.edu/viewdoc/download? doi=10.1.1.694.8011\&rep=rep1\&type=pdf. Acesso em: 15/11/2017.

SCHWAB, J. Un enfoque práctico como lenguaje para el currículum. IN: SACRISTAN, Gimeno J.; PÉREZ GOMÉZ, A. Compreender y transformar la ensiñanza. 1 ed. Madrid: Morata, 1992.

SILVA, F. C. T.; MENDES, G. M. L. Políticas de Escola e Currículo: algumas notas de análise construídas pelo/no contexto escolar. Ciências Humanas e Sociedade em Revista, v. 34, n. 12, jan / jun, p. 177 190, 2012. Disponível em: http://dx.doi.org/10.4322/chsr.2014.010. Acesso em: 02/09/2017.

TYLER, R. Princípios Básicos de Currículo e Ensino. Porto Alegre: Globo, 1974. 
YOUNG, M. A superação da crise nos Estudos Curriculares: uma abordagem baseada no conhecimento. In: FAVACHO, A. et al. (Org.) Currículo: conhecimento e avaliação. Divergências e tensões. Curitiba: CRV. ed. 2013.

Artigo recebido em: 18/02/2018 Aprovado em: 15/03/2018 Contato para correspondência: Claudia Regina Castellano Losso. E-mail: claudiarcl@yahoo.com.br 